
\title{
Development in the United States
}

Stephenie C. Lemon, Ph.D. ${ }^{1}$, Karin Valentine Goins, MPH ${ }^{1}$, Kristin L. Schneider, PhD ${ }^{2}$, L. Reed,

Department of Psychology, Rosalind Franklin University of Medicine and Science, 3333 Green

${ }^{3}$ Prevention Research Center in St. Louis, Brown School, Washington University in St. Louis, 660 School of Medicine, Washington University in St. Louis, 660 S. Euclid Avenue, St. Louis, MO Carolina-Chapel Hill, 137 E. Franklin Street, Chapel Hill, NC 27514

George Warren Brown School of Social Work, Program for Public Health, Washington ${ }^{7}$ Department of Kinesiology, Kansas State University, 119 Anderson Hall, Manhattan, KS 66506 Ochapalional Health, Colorado School of Public Health,

${ }^{0}$ Department of Social and Behavioral Sciences, School of Public Health, West Virginia

Corresponding Author: Stephenie C. Lemon, Ph.D., Division of Preventive and Behavioral Medicine, Department of Medicine, University of Massachusetts Medical School, 55 Lake Avenue North, Worcester, MA 01655, 508-856-4098 - telephone, 508-856-3840 - fax, Stephenie.Lemon@umassmed.edu. 508-752-9742 (telephone), 508-856-3840 (fax),

Karin.Goins@umassmed.edu. 847-578-3311 (telephone),847-578-8765 (fax), Kristin.Schneider@ rosalindfranklin.edu.314-362-9641 (telephone), rbrownson@wustl.edu. 314-935-0119 (telephone), 314-935-8511 (fax), cvalko@wustl.edu. 919-966-1967 (telephone), 919-966-9800 (fax), kelly_evenson@unc.edu. 314-935-7755 (telephone), 314-935-8511 (fax), aeyler@wustl.edu. 785-532-7771 (telephone), 785-532-6486 (fax), kmhphd@ksu.edu. 303-724-4402 (telephone), jill.litt@ucdenver.edu. 404-413-1133 (telephone), 404-413-1140 (fax), rlyn1@gsu.edu. 303-724-4412 (telephone), hannah.reed@ucdenver.edu. 304-926-0873 (telephone), ntompkins@hsc.wvu.edu. 808-956-5779 (telephone), 808-956-6041 (fax),jmaddock@hawaii.edu. 


\section{Abstract}

Purpose-This study examined municipal officials' participation in built environment policy initiatives focused on land use design, transportation, and parks and recreation.

Design-Web-based cross-sectional survey.

Setting-83 municipalities with 50,000 or more residents in 8 states.

Subjects-453 elected and appointed municipal officials.

Measures-Outcomes included self-reported participation in land use design, transportation, and parks and recreation policy to increase physical activity. Independent variables included: respondent position; perceptions of importance, barriers and beliefs regarding physical activity and community design and layout; and physical activity partnership participation.

Analysis-Multivariable logistic regression models.

Results-Compared to other positions, public health officials had lower participation in land use design (78.3\% vs. $29.0 \%)$, transportation $(78.1 \%$ vs. $42.1 \%)$, and parks and recreation $(67.1 \%$ vs. $26.3 \%$ ) policy. Perceived limited staff was negatively associated with participation in each policy initiative. Perception of the extent to which physical activity was considered in community design and physical activity partnership participation were positively associated with participation in each. Perceived lack of collaboration was associated with less land use design and transportation policy participation, and awareness that community design affects physical activity was associated with more participation. Perceived lack of political will was associated with less parks and recreation policy participation.

Conclusion-Public health officials are under-represented in built environment policy initiatives. Improving collaborations may improve municipal officials' policy participation.

\section{Keywords}

Built Environment; Physical Activity; Municipal Government

\section{Introduction}

Substantial evidence exists for the association of built environment characteristics (i.e., the physical form of communities) with greater physical activity. ${ }^{1-7}$ Public health authorities recommend built environment improvements as a sustainable approach for promoting physical activity and improving public health, ${ }^{8}$ with a major focus on actions at the local/ municipal level. ${ }^{9-12}$ These recommendations recognize that municipal built environment policy change approaches should involve collaboration across positions and departments including elected representatives and officials representing key departments, such as transportation, planning, and parks and recreation.

Public health research on the built environment and physical activity has primarily focused on national and state policy. ${ }^{13,14}$ Different policy processes may occur at the municipal level compared to state and national policy processes. ${ }^{15}$ However, research on municipal policy action to achieve physical activity-friendly environments is sparse. ${ }^{14}$ Qualitative 
studies suggest that factors that affect municipal policy processes include budgetary considerations, rather than objective problem indicators; compatibility with existing policy over other criteria; intergovernmental collaboration, coalition building, staff commitment and the presence of champions. ${ }^{15,16}$ While these studies provide initial insights, additional investigation is warranted to further our understanding of factors that influence municipal officials' participation in built environment policy initiatives.

The goals of this study were to: 1) describe municipal officials' participation in built environment policy initiatives in the domains of land use design, transportation, and parks and recreation, 2) determine differences in participation by job position; and 3) examine factors associated with built environment policy participation.

\section{Methods}

A web-based cross-sectional survey was conducted in 2012 and data were analyzed in 2013. The study was approved by the Institutional Review Boards at eight participating institutions.

\section{Target Population and Enrollment}

This study targeted elected and appointed municipal officials from the 94 cities with 50,000 or more residents in eight states (CO, GA, HI, KS, MA, MO, NC, WV), as determined by the 2010 Census. These states were selected because the investigators' universities are located within them. Elected officials included mayors and municipal legislators (city councilors, aldermen, commissioners, selectmen, policy staff). Appointed officials included city/town managers, and heads of departments of planning, community development, economic development, public works, transportation, engineering, parks and recreation, neighborhood services, and public health. For cities with no municipal public health department, county public health departments were included ( $\mathrm{n}=57)$.

The target sample was identified in two ways. For municipalities with 50,000 to 60,000 residents, municipal websites were searched to identify contact information for eligible officials. For municipalities with populations of at least 60,000 residents, officials were identified from the Municipal Yellow Book (www.leadershipdirectories.com), a proprietary database of officials in U.S. municipalities with populations of 60,000 residents and above. Municipal websites were used to complete missing contact information.

\section{Survey Administration}

A standardized administration protocol was followed. Personalized email invitations first explained that they were asked to participate because researchers' were interested in the thoughts of municipal government officials on community layout and design, physical activity and health. The survey link brought them to a consent form that reiterated this initial description and expanded on it by noting that local government officials from 8 states had been invited to participate. This description assured confidentiality and provided investigator contact information for the respective state and the coordinating institution. 
After one week all non-responders who did not actively refuse participation received an email reminder. For subsequent non-respondents, up to three telephone reminders were made over a 5-week period, terminating once contact was made or an individual was determined to no longer hold their position. Survey links were resent upon request, and survey invitations were sent to individuals identified as replacements for those who no longer held positions and as newly eligible. Participants from six states were invited to enter a raffle for one of ten $\$ 25$ gift cards after completing the survey (two institutions did not allow raffles and thus no incentives were offered in those states).

\section{Survey Development}

Survey item development used a five-step process: 1) key informant interviews with five municipal officials and two academicians (political science, economics) to better understand the built environment decision making process and the role of political and public support; 2) a comprehensive literature review to identify existing measurement items corresponding to relevant constructs; 3 ) investigator consensus on selection of specific measures, including modifications of existing surveys and creation of new items; 4) cognitive interviews of the draft survey with four municipal officials to ensure comprehension and relevance; and 5) programming the 43-item survey in Qualtrics and conducting usability testing with research staff and seven municipal officials. The survey is available at http://paprn.wustl.edu/toolsand-resources/Pages/Tools.aspx. ${ }^{17}$

\section{Measures}

\section{Participation in built environment policy}

Participants were asked to indicate (yes/no) whether they had ever participated in the development, adoption or implementation of: 1) municipal land use policy to increase mixed use, density, street connectivity, or pedestrian or bicycle access; 2) municipal public works or transportation policy to increase pedestrian or bicycle safety or accommodation; and 3) municipal parks and recreation policy to increase public access. Policy was defined as an ordinance or bylaw, plan, design standards, reallocation of existing funding, or new funding. These definitions were established as relevant for local government through our formative research. The web-based survey program enabled use of "roll-over definitions", which appeared in a different color and made the definitions available to respondents prior to answering each stem question (transportation, land use, parks and recreation). For each of the three stem questions, participants who selected "yes" were asked to indicate if they had participated in the five specific policy types (ordinance or bylaw; plan; design standards; reallocation of existing funding; and new funding).

\section{Position}

Participants chose their current position from one of seven mutually exclusive categories (public health, planning, transportation or public works, economic or community development, parks and recreation, mayor or city manager, and other municipal legislator). Public health was used as the referent category because of our interest in comparing the experiences of public health officials with those more traditionally involved in built environment policy. 


\section{Perceived importance}

How important physical activity is to the day-to-day responsibilities of their current position was rated on a five-point scale, with a range of not at all important to extremely important. ${ }^{18}$ Importance in their current position to help create an environment where people can be physically active ${ }^{19}$ was rated on a five-point scale ranging from not at all important to extremely important. Perception of how supportive residents in their community are of local government action to address physical activity was rated on a five-point scale, with a range of not at all supportive to extremely supportive.

\section{Barriers}

Five perceived barriers that could be amenable to intervention were assessed. Perception of the extent to which limited staff; lack of collaboration among departments; lack of political will; opposition from the business community; and opposition from resident ${ }^{18-21}$ are barriers that prevent physical activity from being considered in decision-making about community design and layout in their community, was rated on a five-point scale ranging from not at all to extremely. Previous studies found that financial constraints are a ubiquitous barrier to policy change. ${ }^{19,22,23}$ Strategies to promote policy change will need to be creative and low cost given fiscal realities that are unlikely to change in the near term. Thus, financial barrier were not queried in this study.

\section{Beliefs}

Participants rated beliefs about extent to which their community's design and layout affects physical activity, physical activity is currently considered in decision making about community design and layout in their community, and physical activity should be considered in decision making about community design and layout on a four-point scale, with a range of not at all to very much. ${ }^{19}$

\section{Partnership involvement}

Partnership involvement was measured as current involvement in partnerships that focuses on creating an environment where people can be physically active (yes/no). ${ }^{21}$

\section{Covariates}

Socio-demographic characteristics included gender, race/ethnicity, and education. Two questions assessing political ideology on social and fiscal issues using a 7-point scale (extremely liberal, liberal, somewhat liberal, moderate, somewhat conservative, conservative, very conservative), which were collapsed into 3 categories: liberal (extremely liberal, liberal, somewhat liberal), moderate and conservative (extremely conservative, conservative, somewhat conservative). Participants indicated if they lived in the municipality in which they work (yes/no) and if they walked or bicycled for transportation in the past week (yes/no). State was also included as a covariate.

\section{Statistical Analysis}

Analyses were performed using SAS version 9.3. Descriptive statistics were generated for all variables. Means and standard deviations of independent variables were calculated 
overall and by position. One-way analysis of variance was used to assess statistically significant differences across position. Policy participation was determined separately for transportation, land use design and parks and recreation, both overall (any participation) and for each of the five policy types investigated, for the total sample and stratified by position. Chi-square statistics were computed to test for statistically significant differences. Three multivariable logistic regression models examined the association of independent variables simultaneously with participation in transportation, land use design, and parks and recreation policy. Perception variables were treated as continuous variables, with higher scores indicating increasing agreement with the item. Collinearity was assessed in the modeling process by estimating tolerance and variance inflation factors. Two variables were determined to have a high degree of collinearity (how important physical activity is to the day-to-day responsibilities of their current position and the importance in their current position of helping to create an environment where people can be physically active). Therefore, the latter variable was not retained in multivariable models. Models adjusted for each potential confounder. Position was not included in multivariable models because small cell sizes for this variable produced unstable estimates.

\section{Results \\ Survey Participation}

A total of 1845 individuals were initially identified as eligible. During the survey administration process, an additional 32 individuals were identified as eligible and invited to participate. Of these, 104 individuals were deemed ineligible because they no longer worked for the municipality, had a current position not targeted in this study, could not be confirmed as employees (e.g. phone disconnected, name not recognized), or their department was no longer under municipal control. Of the 1773 invited and deemed eligible, 461 (26\%) individuals representing 83 municipalities participated. An additional 8 individuals were excluded from this analysis because they worked in combined municipal departments (e.g. public works and planning), resulting in an analytic sample of 453. Participation rates differed among states, ranging from $12.1 \%$ in MA to $38.7 \%$ in NC. Participation was higher for parks and recreation (45.2\%), community development (41.9\%), planning (42.1\%), public health (39.2\%), and transportation (30.4\%) and lower for mayors/city managers $(19.6 \%)$ and other elected officials (16.7\%).

\section{Description of Study Sample}

Participants were mostly male (70.5\%), white (78.7\%), and held a college degree or higher $(59.5 \%)$ (Table 1). Municipal legislator was the position with the greatest representation (29.6\%) and public health officials comprised the smallest group (8.4\%). Table 2 presents the mean and standard deviation of the independent variables, overall and stratified by position.

\section{Built Environment Policy Participation}

Most respondents reported participation in development, adoption, or implementation of built environment policy related to: land use (74.2\%), transportation or public works (75.1\%), or parks and recreation (64.2\%) (Table 3). With respect to land use policy, the 
greatest percentage of participants reported experience with plans $(68.7 \%)$ and the smallest percentage reported experience with reallocation of funding (36.4\%). Likewise, for transportation or public works policy, the most participants had experience with plans (67.8\%) and the fewest had experience with reallocation of funding (45.5\%). For parks and recreation policy, plans $(60.0 \%)$ were the most commonly reported experience and ordinance $(39.7 \%$ ) was the least common. Public health officials had the lowest (land use and transportation or public works) and among the lowest (parks and recreation) policy participation (see Table 3).

\section{Factors Associated with Built Environment Participation}

The multivariable models assessing factors associated with each of the three policy types are presented in Table 4. Perception of limited staff was negatively associated with participation in each policy initiative, while the extent to which physical activity was considered in community design and participation in a partnership or coalition to create active community environments was positively associated with participation in each policy initiative.

Perception of lack of collaboration and that community design affects physical activity were associated with decreased land use design and transportation policy participation. Perception of lack of political will was associated with decreased parks and recreation policy participation.

As previously described, position was not included in the models. We examined the extent to which including position attenuated the associations of the other independent variables with the three policy participation outcomes: the association between the item assessing perception of the extent to which physical activity is currently considered in community design was attenuated for land use design ( $\mathrm{p}=.10)$, transportation $(\mathrm{p}=.09)$, and parks and recreation $(\mathrm{p}=.12)$ policy participation, although the direction remained the same. All other effect estimates and associated $95 \%$ confidence intervals remained similar.

\section{Discussion}

Achieving active community environments will require a coordinated approach across multiple sectors. This study is among the first to examine the experience of a wide range of municipal officials with built environment policies that impact physical activity. The majority reported participating in the development, adoption or implementation of transportation, land use and parks and recreation policy related to physical activity.

Position was an influential variable, with policy participation high within professional domain and among elected officials and city managers. The picture was more complex for officials' policy involvement outside their domain. Substantive differences between the level of experience of public health officials and that of other municipal officials were observed. Public health officials reported least experience with parks and recreation policy, a somewhat surprising finding given long recognition of the health-promoting qualities of parks. They reported low participation in land use policy and transportation/public works policy, consistent with previous findings. ${ }^{24,25}$ It will be critical to boost this participation going forward, as research has demonstrated that health departments most successful at built 
environment participation engage directly in land use and transportation processes and that consistent engagement is related to success. ${ }^{21}$

The lack of association between importance of physical activity to job responsibilities and policy participation presents an opportunity for municipal or department-specific performance measures related to physical activity. Performance measurement indicators (for example, miles of sidewalks or complete streets added, percent increase in park utilization) could institutionalize the prioritization of physical activity, and researchershave noted that actions with short term measurable results are particularly influential at the municipal level. ${ }^{26}$ Municipal performance measurement plans can leverage ongoing initiatives of the International City/County Management Association's Center for Performance Measurement, ${ }^{11}$ and the US Environmental Protection Agency. ${ }^{27}$ No associations were observed between resident support and participation in the policies examined in this study. It seems reasonable to expect leaders to support efforts where they perceive at least tacit community support, so this merits further exploration.

This study assessed five potential perceived barriers that could be amenable to intervention. While political will was the highest rated perceived barrier overall, it was only associated with parks and recreation policy participation. Limited staff was associated with each policy domain and may reflect actual lack of resources and dedicated staff time as well as lack of prioritization of built environment initiatives. Perceived lack of collaboration was associated with lower participation in both land use design and transportation policy, but not parks and recreation policy. This difference may reflect actual experiences of project silos within parks and recreation, as well as possible difficulty engaging in land use and transportation policy change because of the complicated networks of publics works, planners and engineers that may be difficult for public health officials in particular to navigate. ${ }^{28}$

Awareness that community design affects physical activity was associated with both land use design and transportation policy participation, while perception of the extent to which physical activity is considered in community design and layout was associated with all three policy domains. While we cannot say for certain whether awareness precipitates participation or vice versa, the association between awareness and participation offers a promising avenue for further exploration for policy advancement.

Being a member of a community partnership and/or coalition to create environments that support physical activity was positively associated with policy participation. This has been previously reported and highlights that such partnerships are important catalysts for built environment change. ${ }^{15,16}$ While causality cannot be established given the cross-sectional nature of the study, partnership participation may influence beliefs and actions to make community design decisions that positively affect physical activity, and officials drawn to participation because of their own values will also bring needed expertise to these collaborations. ${ }^{24,}{ }^{29} \mathrm{We}$ also observed that public health officials were more likely than other officials to participate in such partnerships, yet were less likely to have policy participation experience. Partnerships to increase physical activity are a community health tool. Participation in community health partnerships is normative for many health 
departments and might not distinguish individuals with policy experience from those without as much as it might for officials from other positions.

Strengths of this study include a sample inclusive of multiple disciplines that affect the built environment at the municipal level, and inclusion of urban municipalities of varying sizes from eight U.S. states. This study has limitations that must be acknowledged. The study had a low response, which was likely influenced by factors like busy schedules, survey timing at the end of the fiscal year, restricted Internet access or spam filters at worksites, and inaccurate email addresses. This is similar to response rates observed in other studies of policy makers. ${ }^{19,30}$ The low response rate could have biased results. For example, those more interested in or with more experience with the topic may have been more likely to respond, which could over-estimate the extent to which municipal officials participate in built environment policy. The cross-sectional study design limits causal inference and selfreported data is prone to inaccuracies and social desirability bias, including potential overreporting of policy participation. We intentionally assessedpolicy participationwith a single item and assessed application of levers common across municipal policy domains rather than assess officials' participation as a linear process. During survey development our key informants emphasized that actors at the municipal level participate in policy change in an iterative fashion, supporting this approach. However, opportunity for policy participation may not be ubiquitous. Policy initiatives such as those investigated in this study may not occur routinely. When such policy initiatives occur, participation may not be at the discretion of the individual. Factors that can influence participation include awareness of the initiative, being invited to participate by others in different departments, having statutory or other authority to participate, and having permission from a supervisor to participate. This study was not designed to differentiate reasons for participating or not participating in built environment policy. Future studies aiming to further understand or improve policy participation should take these factors into consideration.

\section{Conclusions}

Municipal policy change to the built environment for improving physical activity opportunities requires collaboration among a range of actors and possibly reorientation of longstanding practices. This study identified differences in participation by policy type and position and correlates of participation. Results can provide guidance for advancing policy research and for change to achieve active community environments. In particular, strategies to increase public health officials' involvement in the built environment process, such as performance measurement and professional development on topics related to other disciplines, such as planning and transportation, need to be prioritized by municipalities and professional organizations.

\section{SO WHAT? Implications for Health Promotion Practitioners and Researchers What is already known on this topic?}

The cross-sectional association of built environment characteristics with higher physical activity is well-documented, and built environment improvements are a sustainable approach for promoting physical activity and improving public health. Built environment policies 
occur largely at the local/municipal level and require participation among elected and appointed officials.

\section{What does this article add?}

This study identified factors associated with participation in built environment policy among municipal officials. Differences in participation by policy type and position were identified, with public health officials having low participation rates. Correlates of participation are also identified.

\section{What are the implications for health promotion practice or research?}

Understanding factors that influence municipal officials' participation in built environment policy initiatives is a first step toward educational approaches to promoting built environment factors among this population. Results can provide guidance for advancing policy research and for change to achieve active community environments.

\section{Acknowledgements}

This study was funded by the Centers for Disease Control and Prevention (CDC) Cooperative Agreement Number U48/DP001933 from the CDC, Prevention Research Centers Program, Special Interest Project 09-10: Physical Activity Policy Research Network. The content is solely the responsibility of the authors and does not necessarily represent the official views of the CDC. The authors have no declared conflicts of interest. The authors thank the following individuals for their assistance with this project: Sarah Evers, Caitlin Lawrence, Joseph Lightner, Ashley Raethel, and Carson Smith for data collection; Mary Ellen Blunt and Jonathan Church for their assistance with instrument development; and Karen Ronayne for administrative and manuscript preparation assistance.

\section{References}

1. Heath GW, Brownson RC, Kruger J, Miles R, Powell KE, Ramsey LT. The effectiveness of urban design and land use and transport policies and practices to increase physical activity: A systematic review. Journal of Physical Activity and Health. 2006; 3(Suppl 1):S55-S76.

2. Ferdinand AO, Sen B, Rahurkar S, Engler S, Menachemi N. The relationship between built environments and physical activity: A systematic review. Am J Public Health. 2012; 102:e7-e13. [PubMed: 22897546]

3. Fenton M. Community design and policies for free-range children: Creating environments that support routine physical activity. Child Obes. 2012; 8:44-51. [PubMed: 22799480]

4. Sallis JF, Floyd MF, Rodriguez DA, Saelens BE. Role of built environments in physical activity, obesity, and cardiovascular disease. Circulation. 2012; 125:729-737. [PubMed: 22311885]

5. McCormack GR, Shiell A. In search of causality: A systematic review of the relationship between the built environment and physical activity among adults. Int J Behav Nutr Phys Act. 2011; 8:125. [PubMed: 22077952]

6. Ding D, Gebel. Built environment, physical activity, and obesity: What have we learned from reviewing the literature? Health Place. 2012; 18:100-105. [PubMed: 21983062]

7. Ding D, Sallis JF, Kerr J, Lee S, Rosenberg DE. Neighborhood environment and physical activity among youth a review. Am J Prev Med. 2011; 41:442-455. [PubMed: 21961474]

8. Keener, D.; Goodman, K.; Lowry, A.; Zaro, S.; Kettel, KL. Recommended community strategies and measurements to prevent obesity in the United States: Implementation and measurement guide. US Department of Health and Human Services, Centers for Disease Control and Prevention; Atlanta, GA: 2009.

9. Robert Wood Johnson Foundation. Leadership for healthy communities: Action strategies toolkit. 2009. Available at: www.leadershipforhealthycommunities.org. Accessed August 10, 2013

10. Community Prevention Services Taskforce. Guide to community prevention services. Environmental and policy approaches: Street-scale urban design and land use policies. 2011. 
Available at: www.thecommunityguide.org/pa/environmental-policy/streetscale.html. Accessed August 28, 2013

11. Khan LK, Sobush K, Keener D, et al. Recommended community strategies and measurements to prevent obesity in the United States. MMWR Recomm Rep. 2009; 58(RR-7):1-26. [PubMed: 19629029]

12. Transportation Research Board. Institute of Medicine of the National Academies. Does the built environment influence physical activity? Examining the Evidence --Special Report 282. 2005

13. Bernier NF, Clavier C. Public health policy research: Making the case for a political science approach. Health Promot Int. 2011; 26:109-116. [PubMed: 21296911]

14. Aytur SA, Rodriguez DA, Evenson KR, Catellier DJ, Rosamond WD. Promoting active community environments through land use and transportation planning. Am J Health Promot. 2007; 21(4 Suppl):397-407. [PubMed: 17465186]

15. Liu X, Lindquist E, Vedlitz A, Vincent K. Understanding local policymaking: Policy elites' perceptions of local agenda setting and alternative policy selection. The Policy Studies Journal. 2010; 38:69-74.

16. Salvesen D, Evenson KR, Rodriguez DA, Brown A. Factors influencing implementation of local policies to promote physical activity: A case study of Montgomery County, Maryland. J Public Health Manag Pract. 2008; 14:280-288. [PubMed: 18408553]

17. Centers for Disease Control and Prevention (CDC). Physical Activity Policy Research Network (PAPRN). Available at: http://paprn.wustl.edu. Accessed January 27, 2014

18. Dill J, Howe D. The role of health and physical activity in the adoption of innovative land use policy: Findings from surveys of local governments. J Phys Act Health. 2011; 8(Suppl 1):S116124. [PubMed: 21350252]

19. Hollander M, Martin SL, Vehige T. The surveys are in! The role of local government in supporting active community design. J Public Health Manag Pract. 2008; 14:228-237. [PubMed: 18408547]

20. Goins KV, Schneider KL, Brownson R, et al. Municipal officials' perceived barriers to consideration of physical activity in community design decision making. J Public Health Manag Pract. 2013; 19(3 Suppl 1):S65-73. [PubMed: 23529058]

21. Kuiper H, Jackson RJ, Barna S, Satariano WA. Local health department leadership strategies for healthy built environments. J Public Health Manag Pract. 2012; 18:E11-23. [PubMed: 22286292]

22. Evenson KR, Aytur SA, Satinsky SB, Rodriguez DA. Barriers to municipal planning for pedestrians and bicyclists in North Carolina. N C Med J. 2011; 72:89-97. [PubMed: 21721492]

23. Collins PA, Hayes MV. Examining the capacities of municipal governments to reduce health inequities: A survey of municipal actors' perceptions in Metro Vancouver. Can J Public Health. 2013; 104:e304-310. [PubMed: 24044470]

24. Litt JS, Reed HL, Tabak RG, Zieff SG, Eyler AA, Lyn R, et al. Active living collaboratives in the United States: Understanding characteristics, activities, and achievement of environmental and policy change. Prev Chronic Dis. 2013; 10:E19. [PubMed: 23391295]

25. National Association of County and City Health Officials (NACCHO). 2013 National Profile of Local Health Departments. 2013. Available at: http://www.naccho.org/topics/infrastructure/ profile/upload/2013-National-Profile-of-Local-Health-Departments-report.pdf. Accessed January 29, 2014

26. Perdue WC, Stone LA, Gostin LO. The built environment and its relationship to the public's health: The legal framework. Am J Public Health. 2003; 93:1390-1394. [PubMed: 12948949]

27. U.S. Department of Transportation, Office of Planning Environment and Realty. The role of FHWA programs in livability: State of the practice summary. Available at: http:// www.fhwa.dot.gov/livability/state_of_the_practice_summary/research03.cfm. Accessed July 22, 2013

28. Lee M, Rubin V. The state of current practice and next steps for a growing movement: Produced for PolicyLink for the California Endowment. 2007

29. Litt J, Reed H, Zieff SG, et al. Advancing environmental and policy change through active living collaboratives: Compositional and stakeholder engagement correlates of group effectiveness. J Public Health Manag Pract. 2013; 19(3 Suppl 1):S49-57. [PubMed: 23529055] 
30. Brownson RC, Dodson EA, Stamatakis KA, et al. Communicating evidence-based information on cancer prevention to state-level policy makers. J Natl Cancer Inst. 2011; 103:306-316. [PubMed: 21212381] 


\section{Indexing keywords}

1. Manuscript format: (editorial/commentary/concept, literature review, research): research

\section{For research articles}

2. Research purpose: (instrument development, intervention testing/program evaluation, modeling/relationship testing, descriptive): modeling/relationship testing

3. Study design: (randomized trial, quasi-experimental, non-experimental, qualitative, content analysis): non-experimental

4. Outcome measure: (cognitive, behavioral, biometric, morbidity, mortality, productivity, absenteeism, other financial/economic): behavioral

\section{Content focus}

5. Setting: (family, workplace, school, clinical/health care, local community, state/ national): local community

6. Health focus: (fitness/physical activity, intellectual health, medical self care, nutrition, smoking control, social health, spiritual health, stress management, weight control): fitness/physical activity

7. Strategy (education, skill building/behavior change, incentives, policy, culture change, built environment): built environment

8. Target population age: (youth, adults, seniors): adult

9. Target population circumstances (specify all that apply): (Education/income level, geographic location, and race/ethnicity): geographic location 


\section{Table 1}

Description of the study sample $(n=453)$.

\begin{tabular}{|c|c|}
\hline Characteristic & $\%$ of sample \\
\hline \multicolumn{2}{|l|}{ Position } \\
\hline Public health & $8.4 \%$ \\
\hline Planning & $9.9 \%$ \\
\hline Transportation/public works & $14.3 \%$ \\
\hline Community/economic development & $13.7 \%$ \\
\hline Parks and recreation & $13.5 \%$ \\
\hline Mayor/City manager & $10.6 \%$ \\
\hline Municipal legislator & $29.6 \%$ \\
\hline \multicolumn{2}{|l|}{ Gender } \\
\hline Female & $29.5 \%$ \\
\hline Male & $70.5 \%$ \\
\hline \multicolumn{2}{|l|}{ Race/ethnicity } \\
\hline White & $78.7 \%$ \\
\hline African American/Black & $10.0 \%$ \\
\hline Mixed race or Other race & $5.6 \%$ \\
\hline Prefer not to answer & $5.9 \%$ \\
\hline \multicolumn{2}{|l|}{ Education } \\
\hline High school degree or less & $7.8 \%$ \\
\hline Some college/Technical training & $32.6 \%$ \\
\hline College degree or higher & $59.5 \%$ \\
\hline \multicolumn{2}{|l|}{ On social issues do you consider yourself... } \\
\hline Liberal & $38.2 \%$ \\
\hline Moderate & $24.7 \%$ \\
\hline Conservative & $30.2 \%$ \\
\hline Other/Prefer not to answer & $7.0 \%$ \\
\hline \multicolumn{2}{|l|}{ On fiscal issues, do you consider yourself|| } \\
\hline Liberal & $16.9 \%$ \\
\hline Moderate & $26.7 \%$ \\
\hline Conservative & $50.4 \%$ \\
\hline Other/Prefer not to answer & $6.1 \%$ \\
\hline Live in the city in which you work & $78.3 \%$ \\
\hline Walk or bike for transportation in the past week & $36.2 \%$ \\
\hline
\end{tabular}




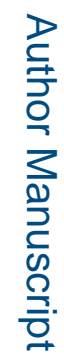

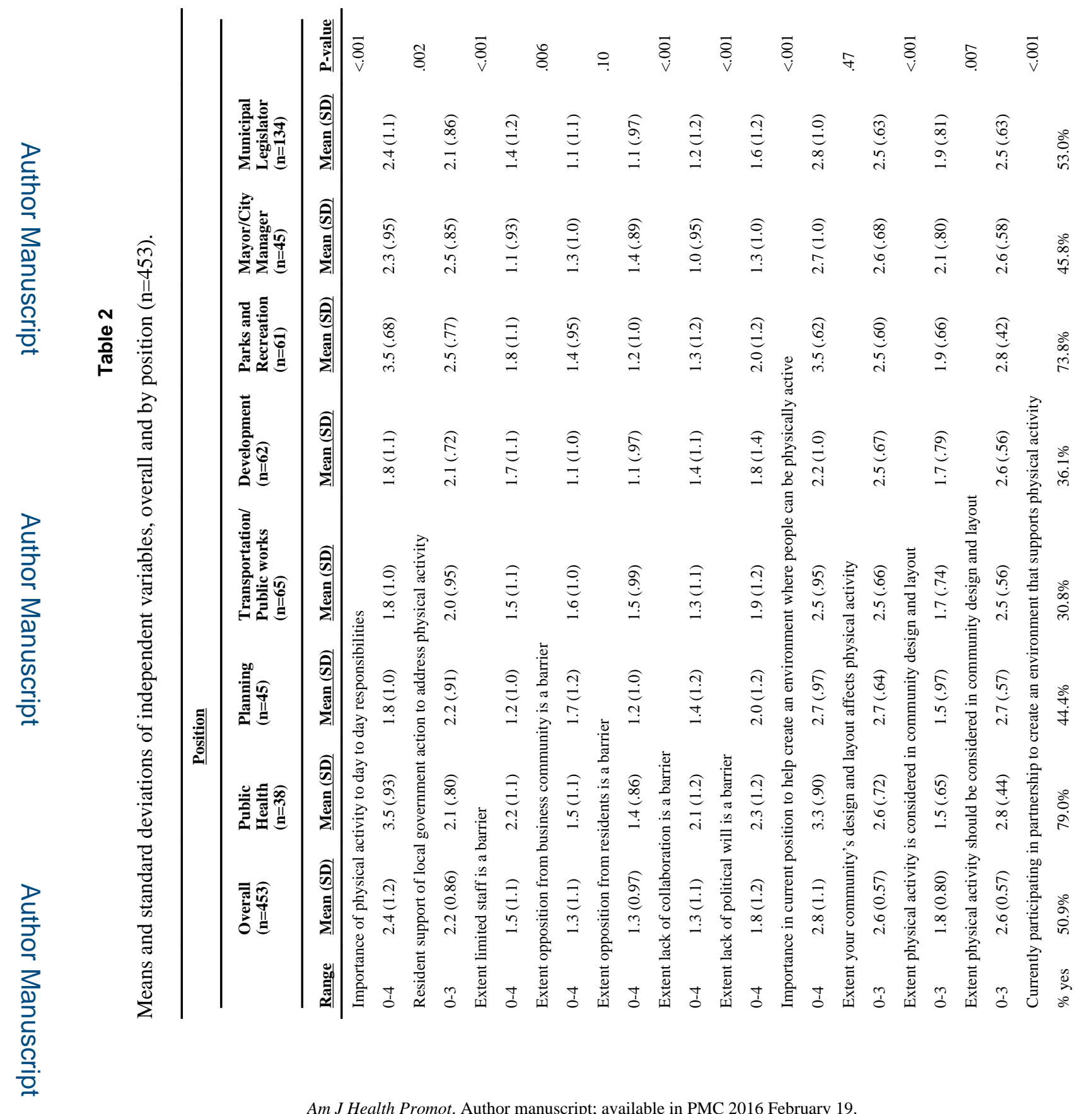




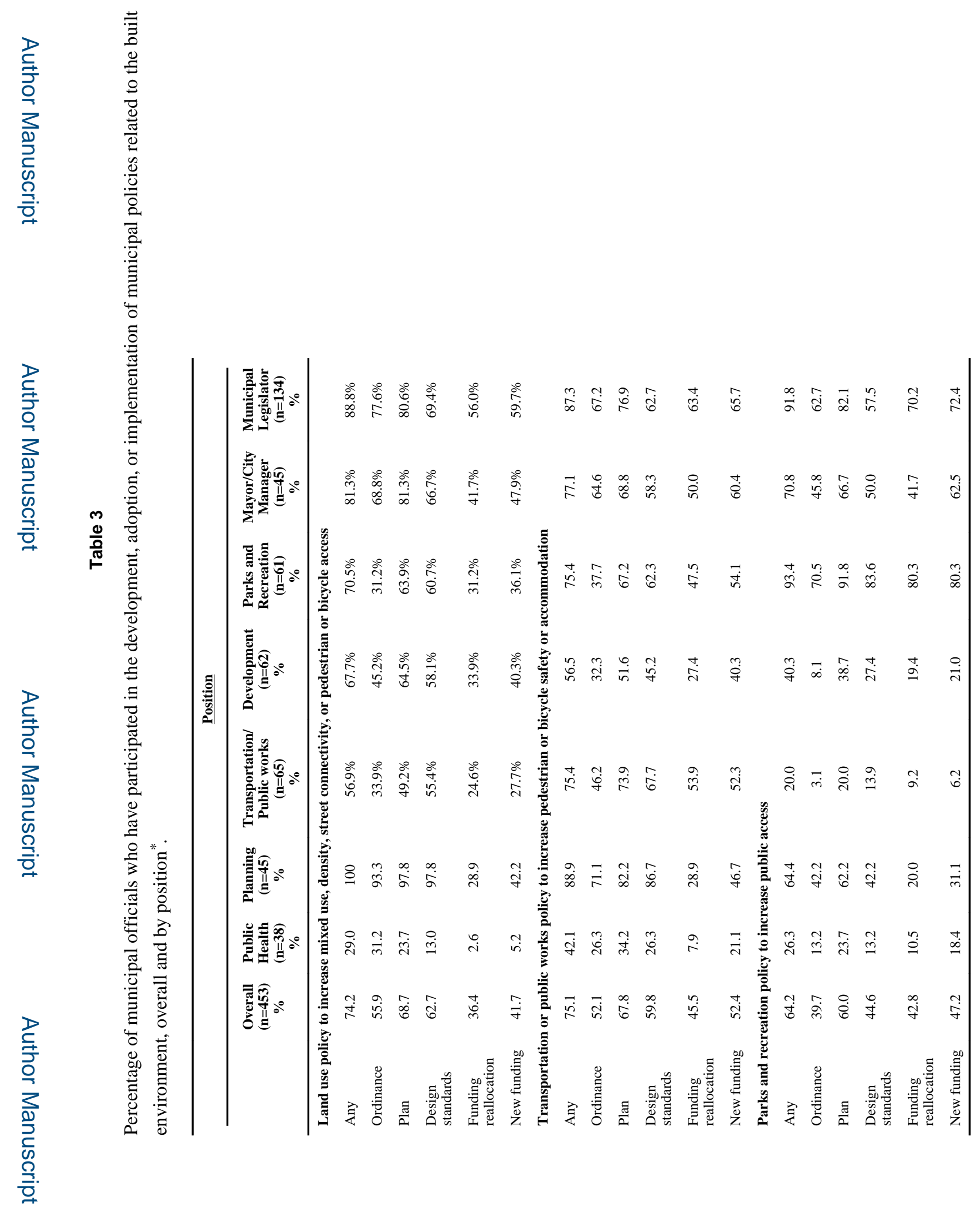

Am J Health Promot. Author manuscript; available in PMC 2016 February 19. 


\section{Table 4}

Multivariable logistic regression models of factors associated with participation in land use design, transportation and parks and recreation policy $(n=453) .{ }^{*}$

\begin{tabular}{|c|c|c|c|}
\hline & $\begin{array}{c}\text { Land Use Design } \\
\text { Policy }\end{array}$ & $\begin{array}{c}\text { Transportation } \\
\text { Policy }\end{array}$ & $\begin{array}{c}\text { Parks and Recreation } \\
\text { Policy }\end{array}$ \\
\hline & $\operatorname{AOR}(95 \%$ CI) & $\operatorname{AOR}(95 \% \mathrm{CI})$ & AOR $(95 \%$ CI $)$ \\
\hline \multicolumn{4}{|l|}{ Characteristics ${ }^{* * *}$} \\
\hline $\begin{array}{l}\text { Importance of physical } \\
\text { activity to day to day } \\
\text { responsibilities }\end{array}$ & $0.94(0.69,1.27)$ & $0.81(0.59,1.10)$ & $1.16(0.93,1.46)$ \\
\hline $\begin{array}{l}\text { Resident support of } \\
\text { local government } \\
\text { action to address } \\
\text { physical activity }\end{array}$ & $1.29(0.94,1.78)$ & $1.21(0.87,1.69)$ & $1.02(0.76,1.37)$ \\
\hline $\begin{array}{l}\text { Extent limited staff is a } \\
\text { barrier }\end{array}$ & $0.81(0.60,0.99)$ & $0.81(0.63,0.98)$ & $0.71(0.57,0.89)$ \\
\hline $\begin{array}{l}\text { Extent opposition from } \\
\text { business community is } \\
\text { a barrier }\end{array}$ & $0.95(0.72,1.29)$ & $1.22(0.91,1.64)$ & $0.99(0.78,1.29)$ \\
\hline $\begin{array}{l}\text { Extent opposition from } \\
\text { residents is a barrier }\end{array}$ & $1.16(0.85,1.59)$ & $1.19(0.87,1.64)$ & $0.87(0.65,1.15)$ \\
\hline $\begin{array}{l}\text { Extent lack of } \\
\text { collaboration among } \\
\text { departments is a } \\
\text { barrier }\end{array}$ & $0.74(0.57,0.95)$ & $0.70(0.54,0.90)$ & $1.08(0.86,1.37)$ \\
\hline $\begin{array}{l}\text { Extent lack of political } \\
\text { will is a barrier }\end{array}$ & $1.08(0.82,1.42)$ & $0.96(0.72,1.26)$ & $0.71(0.55,0.96)$ \\
\hline $\begin{array}{l}\text { Extent your } \\
\text { community's design } \\
\text { and layout affects } \\
\text { physical activity }\end{array}$ & $2.00(1.31,3.07)$ & $1.68(1.07,2.63)$ & $0.74(0.49,1.13)$ \\
\hline $\begin{array}{l}\text { Extent physical activity } \\
\text { is considered in } \\
\text { community design and } \\
\text { layout }\end{array}$ & $1.46(1.02,2.10)$ & $1.48(1.01,2.16)$ & $1.42(1.01,1.99)$ \\
\hline $\begin{array}{l}\text { Extent physical activity } \\
\text { should be considered } \\
\text { in community design } \\
\text { and layout }\end{array}$ & $0.57(0.32,1.03)$ & $0.86(0.50,1.58)$ & $0.90(0.54,1.50)$ \\
\hline $\begin{array}{l}\text { Currently participating } \\
\text { in partnership to } \\
\text { create an environment } \\
\text { that supports physical } \\
\text { activity }\end{array}$ & $1.82(1.20,2.77)$ & $2.92(1.88,4.54)$ & $1.48(1.01,2.16)$ \\
\hline
\end{tabular}

Note. $\mathrm{AOR}=$ adjusted odds ratio; $\mathrm{CI}=$ confidence interval

* Models adjust for gender, education, fiscal political affiliation, social political affiliation, living in community in which respondent works, walking or biking for transportation in the past week and state.

Continuous items, with higher scores indicating increasing agreement with the item. 